\title{
Barriers to HIV testing among mothers at a maternity ward in Phnom Penh, Cambodia
}

Kanal Koum*1, Sasaki Yuri1,2, Kakimoto Kazuhiro1,3, Sathiarany Vong1, Shirayama Yoshihisa ${ }^{1,2}$, Ali Moazzam ${ }^{1,2}$, Kuroiwa Chushi1,2 and Shibuya Kenji ${ }^{1,2}$

\author{
Address: ${ }^{1}$ National Maternal and Child Health Center, Phnom Penh, Cambodia, ${ }^{2}$ Dpt of Health Policy and Planning, University of Tokyo, Japan, \\ Tokyo, Japan and ${ }^{3}$ International Medical Center of Japan, Tokyo, Japan \\ * Corresponding author
}

\begin{abstract}
from Fifth Dominique Dormont International Conference. Mother-to-child transmitted viral diseases: from transmission to children care Paris, France. 26-28 March 2009

Published: 22 July 2009

Retrovirology 2009, 6(Suppl I):OI6 doi:I0.II86/I742-4690-6-SI-OI6
\end{abstract}

This abstract is available from: http://www.retrovirology.com/content/6/SI/OI6

(c) 2009 Koum et al; licensee BioMed Central Ltd.

\section{Introduction}

As a response to the shift in epidemic transmission, prevention of mother to child transmission (PMTCT) services have been expanded in Cambodia. However, the improvement of the acceptance for HIV testing and counselling is still challenging even after the ministry of health in Cambodia adopted provider-initiated HIV testing and counselling (PITC) policy. The objective of this study was to investigate the accessibility of HIV testing and its barriers among mothers at maternity ward in Phnom Penh where the PITC approach had been widely offered.

\section{Methods}

This study was a quantitative and cross-sectional assessment of mothers after delivery at National Maternal and Child Health Centre (NMCHC) in Phnom Penh. Randomly selected 599 mothers from October through December 2007 were asked to participate in a half hour's face-to-face interview by trained interviewers.

\section{Results}

Of the 599 mothers, 455 (76\%) had an experience of HIV testing. Most of the mothers got information about HIV testing from health care provider (360: 79.1\%) and mass media (86: $18.9 \%)$. After adjusting by the multivariate logistic regression, need of partner's permission for HIV testing $(\mathrm{OR}=0.27,95 \% \mathrm{CI}=0.14-0.51, \mathrm{p}<0.01)$, low knowledge on HIV prevention and treatment $(\mathrm{OR}=0.38$,
$\mathrm{CI}=0.22-0.66, \mathrm{p}<0.01)$, ANC place out of Phnom Penh $(\mathrm{OR}=0.35,95 \% \mathrm{CI}=0.21-0.58, \mathrm{p}<0.01)$ were found to be barriers to HIV testing.

\section{Discussion}

Three factors were found to be barriers to HIV testing: partner's permission, low knowledge on HIV prevention and treatment, and place of ANC. It is necessary to provide education and quality counselling not only for mothers but also for their partners even in PITC strategy. In addition, access of pregnant women to HIV testing and counselling services in rural areas should be improved through strategic approaches such as efficient utilization of human resources. 